\title{
JÓ JOAQUIM E LIVÍRIA: ENTRE O DESENREDO DA TRADIÇÃO E O PROTAGONISMO FEMININO
}

\section{André Tessaro Pelinser* João Claudio Arendt* *}

Resumo: A ficção de João Guimarães Rosa notabiliza-se por sua capacidade de recorrer a sujeitos deslocados e incomuns sob diversos aspectos, construindo tramas nas quais personagens impares adquirem protagonismo. Dentre eles, no âmbito deste trabalho, ganha destaque Livíria, mulher cujos nomes anagramáticos (Rivília, Irlivia ou ainda Vilíria) parecem velar e, ao mesmo tempo, desvelar sua importância na narrativa do conto intitulado "Desenredo". Com isso em vista, procura-se lançar luzes sobre os aspectos que fazem que, por um lado, embora a narração confira a Jó Joaquim os papéis de protagonista da história e de autor do "desenredo", por outro, é Livíria quem protagoniza não um, mas dois triângulos amorosos, e serve de princípio motor à narrativa, subvertendo a estrutura social de uma pequena comunidade interiorana. Nessa linha, o feminino articula-se não como simples pivô da traição, mas antes como elemento primeiro de um caso de amor dominado pela mulher que possuía "o pé em três estribos".

Palavras-chave: João Guimarães Rosa. Tutameia. Desenredo.

M esmo para os padrões da ficção de Guimarães Rosa, o volume de contos intitulado Tutameia é caso ímpar. Última obra publicada ainda em vida pelo autor, o conjunto, reunindo trabalhos esparsamente divulgados em revistas e jornais ao longo dos anos anteriores, não constitui simples apanhado de textos. O apuro da organização autoral faz-se visível, de imediato, pela presença de dois índices: um "Sumário", situado no início da obra, e um "Índice de releitura", posto ao final. 
É de notar que as semelhanças entre ambos os índices são muitas, a começar pela disposição em ordem alfabética dos títulos das narrativas e pelas duas epígrafes emprestadas de Schopenhauer. Nos dois índices, os únicos textos que rompem a ordenação são "Grande Gedeão" e "Reminisção", os quais, situados após "João Porém, o criador de perus", formam as iniciais do autor: J. G. R. O que diferencia o "Sumário" do "Índice de releitura" é que os quatro prefácios presentes na obra figuram separados no segundo índice, dispostos antes dos demais textos e identificados como prefácios de fato, enquanto anteriormente obedeciam à mesma ordem alfabética. A despeito disso, evidentemente, sua posição interna não muda, já que os "prefácios" seguem intercalados entre as demais narrativas. De resto, ao leitor acostumado com a inventividade rosiana não deveria causar surpresa a diluição de quatro prefácios ao longo da obra. Conforme Paulo Rónai (1991, p. 529), "Prefácio por definição é o que antecede uma obra literária. Mas no caso do leitor que não se contenta com uma leitura só, mesmo um prefácio colocado no fim poderá ter serventia".

Com efeito, é interessante verificar certa complementaridade entre os dois indices, a qual transcende a simples ideia de "releitura" e se faz visivel nas epígrafes escolhidas por Guimarães Rosa. Na primeira delas, Schopenhauer é evocado para anunciar, já na abertura, que uma segunda leitura será necessária: "Daí, pois, como já se disse, exigir a primeira leitura paciência, fundada em certeza de que, na segunda, muita coisa, ou tudo, se entenderá sob luz inteiramente outra" (ROSA, 2001, p. 5). Ao final do volume, o conceito se completa quando Schopenhauer ressurge para tranquilizar o leitor atônito: "Já a construção, orgânica e não emendada, do conjunto, terá feito necessário por vezes ler-se duas vezes a mesma passagem" (ROSA, 2001, p. 266).

Trata-se, portanto, de mais do que apenas reler o volume, mas ter ciência de que há sentidos escondidos sob a superficie, os quais são por vezes extremamente contraditórios entre si. É o que ocorre com "Desenredo", narrativa que interessa a esta reflexão. Nela, conta-se a história de Jó Joaquim, que, amante de uma mulher casada, acaba por descobrir que ela possuía um segundo amante. Este último é morto pelo marido traído, que foge e também termina por morrer. Jó Joaquim casa-se, então, com a mulher, mas em pouco tempo a surpreende com outro homem e a expulsa de casa. Ele fica, no entanto, tão infeliz, que decide reescrever o passado com o intuito de redimir publicamente e para si mesmo a ex-esposa.

Marcado por diversas características exemplares da ficção de Guimarães Rosa, o conto reelabora poeticamente elementos da cultura popular. A esse propósito, são ilustrativos segmentos como "era infinitamente maio" (ROSA, 2001, p. 72) e "Vá-se a camisa, que não o dela dentro" (ROSA, 2001, p. 74). Esse segundo excerto evidencia o procedimento sistematicamente levado a cabo por Guimarães Rosa ao aproveitar ditados populares, insuflando-os de novidade poética, o que faz que suas narrativas fujam ao lugar-comum e evitem as formulações banalizadas pelo uso cotidiano da linguagem ${ }^{1}$. Engana-se, porém, quem pensar que se 
trata de mero artifício retórico para causar estranheza, pois um exame cuidadoso das tramas elaboradas pelo autor não deixará de revelar como o inusitado da linguagem compactua com o insólito dos enredos e com suas incomuns personagens. Nisso reside um importante sentido de organicidade, que impede que as soluções estilísticas soem artificiais.

Uma ilustração precisa dessa técnica pode ser encontrada no primeiro excerto anteriormente apresentado. Ao assinalar que "era infinitamente maio", o narrador não procura simplesmente marcar o tempo - até porque seria uma marcação imprecisa demais -, assim como o autor não visa desestabilizar o leitor sem maiores consequências. Alçado à infinitude, o mês de maio sugere desde as primeiras linhas do conto uma dimensão ilimitada do amor, aspecto que terá desdobramentos significativos ao final do texto. Por óbvio, a escolha não é isenta, uma vez que o mês de maio, associado no hemisfério Norte à chegada da primavera e ao florescimento da natureza, representa a vida que renasce após o clima escuro e frio do inverno. Daí, inclusive, sua possivel vinculação, no âmbito do imaginário, à ideia do casamento e à figura das noivas, sempre celebradas com flores e grinaldas, e circundadas por uma imagética clara, solar, positiva.

A respeito dessa compreensão, é digna de nota uma das acepções fornecidas pelo Dicionário Houaiss da Língua Portuguesa para o termo "maio": "fig. tempo marcado por flores e prazeres; primavera (viveram seu casamento como um m. perpétuo)" (HOUAISS; VILLAR, 2009, p. 1218). Muito embora no Brasil esse período do ano não esteja vinculado à primavera, parece lícito, pois, assumir que tal imaginário tenha sido incorporado culturalmente, dadas as seguidas referências a esse conjunto de imagens. Nesse sentido, "Jó Joaquim pegou o amor" (ROSA, 2001, p. 72) no momento mais propício do ano, quando, tomado por infinito, acompanhará a personagem pelo restante de sua trajetória.

A narrativa apresenta, ainda, a típica erudição rosiana capaz de unir filosofia e conhecimento bíblico a um fugaz lance de aventura em uma aldeia interiorana, envolvendo personagens excêntricas e improváveis. Veja-se como a trama foge completamente "à lógica, desde que Aristóteles a fundou” (ROSA, 2001, p. 74), porque Jó Joaquim - nome que recende duplamente ao universo religioso - "queria apenas os arquétipos, platonizava" (ROSA, 2001, p. 74). Tais elementos não só conferem unidade às histórias de Tutameia, como também se prestam a leituras plurais, revelando novos significados conforme o foco por que são vistos, de modo que corroboram as epígrafes do volume.

No entender de Maria Zilda Cury (2001, p. 98), “O conto 'Desenredo' acentua o poder da narrativa de 'contar' o vivido, mas, sobretudo, seu poder de ultrapassá-lo, de modificar e inventar 'o real"'. Não surpreende, pois, que a trama inicie por uma fórmula altamente oralizante - a saber: "Do narrador a seus ouvintes:" (ROSA, 2001, p. 72) - e encerre assumindo um caráter fabular - "E pôs-se a fábula em ata" (ROSA, 2001, p. 75) -, de maneira que seu compromisso de verossimilhança torna-se amplo o suficiente para permitir o "refazer-se da história”. Ainda segundo Cury (2001, p. 98-99), "enredo" significa literalmente confusão de fios, e figurativamente uma intriga. Com o prefixo de negação "des", o enredo torna-se, ao mesmo tempo, uma história que acaba bem e uma coisa que se destrama, que se desmantela. Há, nessa perspectiva, uma ambiguidade basilar anunciada desde o título, a qual enseja a duplicidade de entendimentos que se pode formular acerca dos papéis das personagens. 
O ponto de interesse dessa dualidade é que, embora o "desenredar" da história seja levado a cabo pela personagem principal, Jó Joaquim, tal procedimento não seria possivel sem o que aqui entendemos como o protagonismo da mulher que possuía "o pé em três estribos" e quatro nomes: Livíria, Rivília, Irlivia ou Vilíria. Ainda que haja espaço para uma infinidade de interpretações, parece correto admitir que Jó Joaquim não alcançaria a notoriedade sem a libertária ação do elemento feminino. Afinal, já nas primeiras linhas fica-se sabendo que o homem "Tinha o para não ser célebre. Com elas quem pode, porém? Foi Adão dormir, e Eva nascer. Chamando-se Livíria, Rivilia ou Irlívia, a que, nesta observação, a Jó Joaquim apareceu” (ROSA, 2001, p. 72).

A propósito de sentenças como "Tinha o para não ser célebre", Rónai (1991, p. 533) destaca que "Dentro do contexto, tais expressões claramente indicam algo mais do que a simples negação do antônimo: aludem a uma nova modalidade de ser ou de agir, a manifestações positivas do que não é”. Assim, ao mesmo tempo em que Jó Joaquim está inegavelmente inscrito sob o signo da negação, o estilo rosiano insinua como aspecto positivo a simplicidade humana de um sujeito a quem estaria reservado um destino singelo. Dentro de si, Jó Joaquim tinha o suficiente para uma existência pacata, daquelas que não figurariam nas páginas da grande literatura. Mas foi Livíria aparecer e o rumo da vida de Jó mudar.

Seria Livíria a causa da perdição ou, pelo contrário, a possibilidade de salvação, de "celebrização" do homem? É evidente que o paralelo com Adão e Eva pode apontar para o pecado primordial, para a mulher seduzida pela serpente e responsável pela expulsão do ser humano do paraíso. Guimarães Rosa, entretanto, dá mostras de inverter - ou no mínimo complexificar - o mito bíblico, uma vez que Livíria não está na posição de seduzida, mas na de sedutora. Note-se que Eva é persuadida pela serpente a experimentar a maçã e com isso atrai a desgraça sobre si mesma e Adão. Contrariamente, a inusitada mulher interiorana apresentada em "Desenredo" é expulsa do paraíso não por ser tentada por algum fruto proibido, mas por tomar as rédeas de seus desejos e se tornar o próprio objeto cobiçado. Mais do que isso, não precisa dos serviços da serpente, uma vez que ela atua para alcançar suas vontades. Nesse processo, a amante acaba por propiciar ao parceiro a descoberta de um novo olhar sobre seu próprio destino. E com esse olhar, Jó Joaquim poderá em seguida trazê-la de volta, poderá reabilitar o paraíso à frente de todos.

A ligação com o universo bíblico, de resto, é uma constante na literatura de Guimarães Rosa. Não à toa, a escolha do nome do protagonista do conto repousa sobre um redobramento do motivo bíblico da provação do sujeito bom ante a dificuldade. O procedimento empregado no texto rosiano, contudo, embaralha as fronteiras entre bem e mal. Está claro que a personagem masculina remete à figura bíblica de Jó, que se tornou objeto de uma aposta entre Deus e Satanás e cuja retidão de caráter foi colocada à prova frente ao mal. No "Livro de Jó", o protagonista é homem exemplar, próspero e temente a Deus, mas se torna alvo de seguidos infortúnios ao ser molestado por Satanás com o aval de Deus. Recaem sobre Jó várias adversidades, que acometem seus bens materiais, seus familiares e, por fim, seu próprio corpo. Nesse momento, enfim, sua esposa o repreende: "Ainda conservas a tua integridade? Amaldiçoa a Deus, e morre" (BÍBLIA SAGRADA, 1969, p. 531). Ainda assim, o homem não se dobra, acabando por conceder a Deus a vitória na disputa. 
Entretanto, enquanto o livro sagrado cristão não nomeia a esposa de Jó e faz que ela pareça desempenhar na história o papel de coadjuvante do Diabo, indicando assim uma reduplicação do pecado original e da culpabilização da mulher (CURY, 2001, p. 101), a narrativa rosiana parece tomar outro rumo. A amante de Jó Joaquim não só é nomeada, como possui quatro nomes, além de atuar arquetipicamente como fonte do bem e do mal a um só tempo. É ela, afinal, quem desestabiliza a vida pacata da cidade do interior, mas também é ela a responsável pela libertação de Jó Joaquim das amarras da estrutura social e pelo desencadeamento da sua capacidade de refazer e recontar o seu destino. Assim, ao invés de aguardar os desígnios divinos, esse Jó rosiano refaz a sua própria história, tendo por princípio motor a força feminina.

Joaquim é outro nome cuja etimologia remonta ao sagrado, tendo seu significado comumentemente associado "àquele que foi preparado por Deus". No conto de Rosa, quem prepara Joaquim para sua nova vida é o elemento feminino. Mas as relações intertextuais não se esgotam aí. Conforme Cury (2001, p. 101-102),

É ainda relevante uma ligação da personagem rosiana com outra personagem bíblica. Trata-se de um texto grego, apócrifo, isto é, que não pertence ao cânone hebraico, que conta a história tipicamente popular da bela Suzana, casta esposa de um certo Joaquim, assediada por dois velhos. Furiosos por sua recusa, eles a acusam de adultério. Condenada à morte, Suzana é salva pelo profeta Daniel, que consegue fazer com que os dois homens caiam em contradição.

A diferença, nesse caso, consiste em que Livíria não é a esposa bíblica e casta. Ela assume o protagonismo de sua sorte ao satisfazer suas próprias vontades, independentemente dos imperativos sociais que deveriam orientar seu comportamento de mulher exemplar, e, assim procedendo, coloca Joaquim, tal qual o profeta Daniel, na posição de legislar sobre os destinos. Com efeito, nesse mundo rosiano em que é a mulher que cavalga, os homens, por vezes, são tangidos sem perceber: "Imaginara-a jamais a ter o pé em três estribos" (ROSA, 2001, p. 73), surpreendera-se Jó Joaquim.

Ao tomar conhecimento da posição subjugada em que se encontrava, o protagonista não a aceita passivamente e interrompe o relacionamento. "Reteve-se de vê-la. Proibia-se de ser pseudopersonagem, em lance de tão vermelha e preta amplitude" (ROSA, 2001, p. 73), sentencia o narrador a respeito do amante desiludido. O feminino, todavia, surge logo recuperado do revés, ao passo que o elemento masculino segue abatido, ressaltando sua incapacidade de fazer frente ao infortúnio: "Ela - longe - sempre ou ao máximo mais formosa, já sarada e sã. Ele exercitava-se a aguentar-se, nas defeituosas emoções" (ROSA, 2001, p. 73). Veja-se que, se tal procedimento pode assinalar certo caráter vil e manipulador inscrito no nome da personagem ${ }^{2}$, também apresenta aspectos positivos ao projetar uma imagem de mulher forte e resoluta, em oposição a um homem que demonstra dificuldade para lidar com as emoções.

Liviria, a bem da verdade, não é uma mulher qualquer. A tomarem-se a sério as epígrafes da obra, releituras do texto rosiano revelam novas camadas de significado, expandindo as suas intertextualidades. Nesse sentido, impossível não vislum-

2 Observe-se o jogo anagramático em que a palavra "vil" está inserida: Livíria, Rivília, Irlívia e Vilíria. 
brar ressonâncias da tradição literária brasileira quando se verifica que a personagem adúltera era caracterizada por insólita fórmula: "olhos de viva mosca, morena mel e pão" (ROSA, 2001, p. 72). Por um processo similar àqueles que, em A angústia da influência, Harold Bloom (1997) denomina "clinamen ou apropriação poética" e "tessera ou completude e antítese", Guimarães Rosa parece desviar-se de seu precursor no último instante, apropriando-se de termos e imagens que lhe seriam característicos, mas conferindo-lhes novos significados. Para Bloom (1997, p. 19$45,49-73$ ), o clinamen ocorre quando o poeta posterior mantém certa cumplicidade em relação a seu predecessor, mas oferece um desvio em sua trajetória, modificando-se em alguma medida no processo, enquanto a tessera corresponde a um ato de completar o precursor por meio da apropriação de determinados termos caracteristicamente seus, mas conferindo-lhes novos significados, como se o precursor tivesse falhado em chegar tão longe. É como se o poeta posterior não apenas respondesse a um enigma, mas convencesse a si mesmo e a seu leitor idealizado de que aquele enigma não poderia ter sido formulado sem ele (BLOOM, 1997, p. 72).

$\mathrm{Na}$ série literária brasileira, outra mulher celebrizou-se por seus "olhos de ressaca" e pela inusitada definição de "cigana obliqua e dissimulada": Capitu. Assim como ela, Livíria é mulher incomum, notável por seus olhos e suas atitudes. Enquanto uma traga tudo o que está ao seu redor à maneira das vagas do mar e seduz pela atitude esquiva, a outra chama a atenção pela vivacidade do olhar inquieto e se torna irresistivel pela beleza morena. Todavia, as duas enfrentam destinos altamente diversos. Desviando-se de seu antecessor Machado de Assis, conforme pressupõe o clinamen, Guimarães Rosa parece a ele se opor e com isso completá-lo, atendendo à tessera.

Trata-se de um reagenciamento especular, no qual os sinais figuram invertidos, dada a existência de outros indícios na filigrana narrativa. $O$ primeiro marido de Livíria, por exemplo, ao apanhar a esposa com outro homem, mata-o e em seguida foge. No exílio, não falece simplesmente: sua morte é motivo de significativa dúvida. "Azarado fugitivo, e como à Providência praz, o marido faleceu, afogado ou de tifo. O tempo é engenhoso" (ROSA, 2001, p. 73). De fato, a engenhosidade do tempo manifesta-se no caráter cíclico da retomada do passado, que ressurge ressignificado. Basta lembrar, por exemplo, que outros homens faleceram por afogamento e por febre tifoide na história literária brasileira: no mundo machadiano já referido, Escobar, possivel amante de Capitu, é vitimado pelo mar em ressaca, enquanto Ezequiel, filho renegado por Bentinho, sucumbe à febre em Jerusalém.

Uma vez mais, as formulações teóricas de Bloom podem iluminar os sentidos cifrados nas diversas camadas narrativas do conto rosiano. Aqui, a retomada de Machado de Assis parece assinalar um redobramento trágico, quando as duas personagens de Dom Casmurro vêm habitar uma só personagem rosiana, inscrevendo-lhe metaforicamente uma dupla morte. A esse procedimento, Bloom (1997) confere o nome de apophrades, definindo-o como os dias sombrios em que os mortos voltam a habitar suas antigas casas. Ocorrendo com os grandes artistas como um amplo movimento revisionário capaz de subverter a tirania do tempo, a apophrades faz-nos acreditar, por um momento de espanto, que os sucessores estão sendo imitados por seus ancestrais. Nesse instante, os poetas mortos retornam, mas com as cores do presente, falando pela voz de seu sucessor, de modo que as realizações do passado parecem devedoras dos sucessos presentes (BLOOM, 1997, p. 141). 
Seria o "Desenredo" uma tentativa de desfazer o enredo trágico de todas as traições a que foi submetido o feminino na história das artes, tendo Capitu como exemplo prototípico nas letras nacionais? Afinal, enquanto Bentinho narra para condenar, o rapsodo rosiano narra para absolver: "os tempos se seguem e parafraseiam-se” (ROSA, 2001, p. 73), não se repetem. Assim que, quando Jó Joaquim, já casado com Livíria, expulsa-a ao descobrir-se também traído, sua atitude parece recuperar catástrofes pretéritas. "Pelo fato, Jó Joaquim sentiu-se histórico, quase criminoso, reincidente" (ROSA, 2001, p. 74). Triplamente irmanado a Bento Santiago em seus dramas, Jó Joaquim é a manifestação em apophrades da personagem machadiana. Por isso, sente-se reincidente no mesmo amargor e na mesma atitude ao expulsar a esposa; por isso, percebe-se histórico ao reencenar a tradição literária; e, por isso, encontra-se no limiar do crime, assim como Bento Santiago, já que não tira a vida de Livíria, da mesma maneira que Bentinho não abrevia a existência dos cachorros que latiam, do filho e da esposa, embora cogite fazê-lo. Ao permitir o retorno dos mortos às suas casas, Guimarães Rosa o faz com voz própria, de modo que não é Bentinho quem fala através de Jó Joaquim, mas é Jó Joaquim quem ressignifica Bentinho. Com isso, o texto rosiano toma rumo diverso, apresenta-se radicalmente único precisamente quando deixa entrever os ecos das vozes do passado.

Corrobora-se, nesse caso, a assertiva sustentada por T. S. Eliot (1950) em seu clássico ensaio "Tradição e talento individual". Naquele texto, o poeta aponta a existência, em leitores e críticos, de uma tendência a insistir, quando se aprecia um autor, nas características que o distingam dos demais. É como se com isso se buscasse encontrar algo de único, individual, uma essência só sua que o separe por completo do restante dos artistas. Procura-se identificar e isolar algo único para que então o artista possa ser apreciado em sua individualidade. Segundo Eliot (1950, p. 48), todavia,

[...] se nos aproximarmos do poeta sem esse preconceito deveremos descobrir que não apenas as melhores, mas as partes mais particulares do seu trabalho talvez sejam aquelas em que os poetas mortos, seus ancestrais, assinalam sua imortalidade mais vigorosamente.

Vale destacar que, desenredando o passado, Jó Joaquim "Expulsou-a, apenas, apostrofando-se, como inédito poeta e homem” (ROSA, 2001, p. 74). No universo vindicativo dos sertões, não é esperado o perdão; é necessária, muitas vezes, a morte para cumprir com as demandas do imaginário social. O Jó sertanejo, então, torna-se inédito homem, interrompendo-se a um passo de satisfazer as regras tácitas que regem a sociedade como espécie de "cimento social", conforme expressão de Maffesoli (2001, p. 76). Mas também, na série literária, Jó Joaquim é inédito, já que Bentinho, por exemplo, não perdoa Capitu. Jó Joaquim é inédito poeta que reescreve a tradição, tornando-se inesperadamente célebre. Nesse sentido, observa-se como a obra ganha força justamente ao dialogar com a tradição, permitindo que as vozes dos mortos se façam ver em seus sucessores. Ao incorporar e ressignificar o discurso pretérito, a obra de Guimarães Rosa possibilita que sejam jogadas sobre si luzes inauditas, e que presente e passado sejam vistos por novos prismas. 
Para tanto, não é o feminino que se modifica; foi Jó Joaquim que "Dedicou-se a endireitar-se" (ROSA, 2001, p. 74). Destramando o passado, começa a redimir a imagem pública da mulher: "Nunca tivera ela amantes! Não um. Não dois" (ROSA, 2001, p. 74). Para demonstrá-lo, foge à matemática e à lógica, recorre a "antipesquisas, acronologia miúda, conversinhas escudadas, remendados testemunhos. Jó Joaquim, genial, operava o passado - plástico e contraditório rascunho. Criava nova, transformada realidade, mais alta. Mais certa?” (ROSA, 2001, p. 74). Ao reformar o rascunho contraditório do tempo pretérito, Jó Joaquim ultrapassa, modifica e reinventa o "real", insuflando a narrativa com seu poder de contar.

Pois, produziu efeito. Surtiu bem. Sumiram-se os pontos das reticências, o tempo secou o assunto. Total o transato desmanchava-se, a anterior evidência e seu nevoeiro. O real e válido, na árvore, é a reta que vai para cima. Todos já acreditavam. Jó Joaquim primeiro que todos (ROSA, 2001, p. 75).

Gilbert Durand (2002), em As estruturas antropológicas do imaginário, aponta um aspecto importante a se considerar acerca da simbologia da árvore. Segundo o autor, a cruz está intimamente ligada à madeira que lhe deu origem, de modo que ambas compartilham uma série de significados. Em sua perspectiva,

A cruz cristã, enquanto madeira erguida, árvore artificial, apenas drena as acepções simbólicas próprias a todo simbolismo vegetal. Com efeito, a cruz é muitas vezes identificada a uma árvore, tanto pela iconografia como pela lenda, tornando-se com isso escada de ascensão, porque a árvore, como veremos, é contaminada pelos arquétipos ascensionais (DURAND, 2002, p. 328-329).

É interessante notar como tais constantes arquetipais permeiam o texto rosiano e contribuem para complexificar seus sentidos. Implicitamente, o narrador de "Desenredo" equipara a situação de Jó Joaquim ao emblema da árvore, para defender que o válido nesses casos é o cerne, a reta ascendente, e não os galhos, as arestas, os detalhes. Em essência, o relevante é o sentimento amoroso que tudo motivou, este tendo a capacidade de conduzir à salvação em situação adversa. Após carregar a cruz penitente do relacionamento malogrado, Jó Joaquim agarra-se à real e válida escada de ascensão representada pelo amor iniciado naquele já referido infinito mês de maio.

Não suficiente, Durand ainda destaca, em sua obra, a proximidade entre as imagens da árvore e do pássaro, que se desdobra de diferentes maneiras nas mais diversas sociedades ao longo da história. Considerando-se o conto aqui em questão, não deixa de chamar a atenção uma certa maneira rosiana com que Durand (2002, p. 342) finaliza seu argumento:

É necessário, com efeito, sublinhar a constante justaposição do simbolismo da árvore e do arquétipo da ave, tanto em certos textos upanixádicos como na parábola evangélica do "grão de mostarda", tanto na tradição chinesa como na árvore Peridex da iconografia medieval. Toda ramagem é convite ao voo.

Se toda ramagem é convite ao voo e o real e válido na árvore é a reta que vai para cima, a narrativa em análise recupera seu poder de devassar novos horizontes 
e apresentar realidades possiveis. A partir da reta ascensional da árvore amorosa nascida em um maio sem limites, a imaginação de Jó Joaquim alça voo e reescreve sua própria história, refazendo conjuntamente a percepção de toda a coletividade.

Livíria, ou Rivilia, ou Irlivia pode, então, retornar sem culpa, para finalmente receber seu quarto nome: Vilíria ${ }^{3}$. Acaba-se, assim, a dúvida lançada no início do enredo, quando se verifica certa imprecisão quanto ao nome da personagem: "Chamando-se Livíria, Rivília ou Irlivia, a que, nesta observação, a Jó Joaquim apareceu" (ROSA, 2001, p. 72). O emprego da conjunção "ou”, quando da primeira menção à mulher que mudaria a vida de Jó Joaquim, garante que o leitor partilhe da incerteza do narrador, nublando por consequência a própria compreensão de quem de fato é Livíria. Ao cabo, a adição da derradeira alcunha contribui para ressignificar todas as designações anteriores, como queriam as duas epígrafes do livro.

Apesar de o quarto nome, Vilíria, iniciar pelo segmento "vil", a personagem não direciona o ser masculino a um destino trágico - da mesma forma que Capitu, a rigor, não conduziu Bentinho ao seu conhecido desfecho, nem Madalena guiou Paulo Honório à amargura, porque, afinal, nesses casos os homens parecem, antes de tudo, responsáveis por suas próprias incapacidades para lidar com o feminino que não se enquadra nos padrões. Nesse sentido, é possível que Vilíria vilipendie mais a ordem social instituída, do que a vida e o destino do homem a quem se une. Levando-se em conta que um dos amantes é assassinado e que o primeiro marido morre no exílio, talvez seja possível perceber na trajetória de Livíria antes um espírito libertário, do que uma atitude vil, posto que em nenhum momento ela dá mostras de conspirar para tais fins.

De qualquer maneira, a colocação da letra "v" (de Vilíria) em primeiro plano no instante final da narrativa promove de imediato as conexões que identificam o anagrama imperfeito de "virilha" inscrito desde o início na existência da personagem, indicando o poder operado por seu sexo de desorganizar o mundo masculino. Sobretudo depois de conhecido e desenredado o enredo, Vilíria pode retornar absolvida de suas ações e do peso da tradição/traição. Jó Joaquim, que era "bom como o cheiro de cerveja" e, portanto, propício a ficar embriagado, inebriou-se por Livíria. Foi ao perder-se por ela que ele se tornou célebre, capaz do "desenredo" que salva aos dois.

\section{Jó JoAguim AND LIVÍRIA: BETWEen THE UNRAVELING OF TRADITION AND THE FEMININE PROTAGONISM}

Abstract: Guimarães Rosa's fiction distinguishes itself for its abitily to deal with characters that are displaced and unusual in several respects, creating plots in which the most unexpected individuals acquire a particular protagonism. Among them, in this paper we cast light upon Liviria, the woman whose anagrammatic names (Rivilia, Irlivia, or yet Vilíria) seem to conceal and at the same time to uncover her importance to the narrative of the short story entitled "Desenredo". Bearing this in mind, we intend to examine some of the aspects

3 Para Ana Maria Machado (1991, p. 7), "no caso específico de Guimarães Rosa, não faltam depoimentos do próprio autor, através do próprio texto, ou em sua correspondência em entrevistas, revelando a importância primordial que para ele assumia a questão do nome próprio e de seu papel significativo". 
that contribute to the perception that, on the one hand, the narration presents Jó Joaquim as not only the proper protagonist but also as the author of the "unraveling" announced by the title; on the other hand, it is Liviria who leads not one, but two love triangles, and acts as the motion principle of the narrative, undermining the rigid social structure of a little community in the countryside. From this perspective, the feminine element becomes not a mere pivot of the infidelity, but the most important element in a love affair ruled by the woman who kept "the foot in three stirrups".

Keywords: João Guimarães Rosa. Tutameia. Desenredo.

\section{REFERÊNCIAS}

ASSIS, Machado de. Dom Casmurro. Porto Alegre: L\&PM, 2011.

BÍBLIA SAGRADA. A. T. Livro de Jó. Brasília: Sociedade Bíblica do Brasil, 1969. p. 531-564.

BLOOM, H. The anxiety of influence: a theory of poetry. 2. ed. New York: Oxford University Press, 1997.

COUTINHO, E. F. Linguagem e revelação: uma poética da busca. O Eixo e a Roda, Belo Horizonte, v. 12, p. 161-173, 2006. Disponivel em: <http://dx.doi. org/10.17851/2358-9787.12.0.160-173>. Acesso em: 15 ago. 2016.

CURY, M. Z. F. Espaços virtuais: o desenredo de Rosa, o desafio de Jó. O Eixo e a Roda, Belo Horizonte, v. 7, p. 93-107, 2001. Disponivel em: <http://www.periodicos.letras.ufmg.br/index.php/o_eixo_ea_roda/article/view/3098/3051 >. Acesso em: 28 ago. 2015.

DURAND, G. As estruturas antropológicas do imaginário. Tradução Hélder Godinho. 3. ed. São Paulo: Martins Fontes, 2002.

ELIOT, T. S. Tradition and the individual talent. In: ELIOT, T. S. The sacred wood: essays on poetry and criticism. 7. ed. London: Methuen \& Co., 1950. p. 47-59.

HOUAISS, A.; VILLAR, M. de S. Dicionário Houaiss da lingua portuguesa. Rio de Janeiro: Objetiva, 2009.

MACHADO, A. M. Recado do nome: leitura de Guimarães Rosa à luz do nome de seus personagens. São Paulo: Martins Fontes, 1991.

MAFFESOLI, M. O imaginário é uma realidade. Revista Famecos, Porto Alegre, n. 15, p. 74-82, ago. 2001.

RÓNAI, P. Tutaméia. In: COUTINHO, E. (Org.). Guimarães Rosa. 2. ed. Rio de Janeiro: Civilização Brasileira, 1991. p. 527-535. (Coleção Fortuna Crítica).

ROSA, J. G. Tutameia (Terceiras estórias). 8. ed. Rio de Janeiro: Nova Fronteira, 2001.

Recebido em outubro de 2016.

Aprovado em junho de 2017. 